Article

\title{
Improving Restorative Maintenance Practices for Mature Permeable Interlocking Concrete Pavements
}

\author{
Kirti Sehgal ${ }^{1, *}{ }^{\mathbb{D}}$, Jennifer Drake ${ }^{1} \mathbb{D}$, Tim Van Seters ${ }^{2}$ and William Kyle Vander Linden ${ }^{3}$ \\ 1 Department of Civil \&Mineral Engineering, University of Toronto, 35 St. George Street, Toronto \\ ON M5S 1A4, Canada; jenn.drake@utoronto.ca \\ 2 Toronto and Region Conservation Authority, 950 Pine Valley Drive, Vaughan, ON L41 1A6, Canada; \\ TVanSeters@trca.on.ca \\ 3 Credit Valley Conservation, 1255 Old Derry Road, Mississauga, ON L5N 6R4, Canada; \\ kyle.vanderLinden@cvc.ca \\ * Correspondence: kirti.sehgal@mail.utoronto.ca; Tel.: +1-647-778-2629
}

Received: 6 October 2018; Accepted: 4 November 2018; Published: 6 November 2018

\begin{abstract}
Permeable Interlocking Concrete Pavements (PICP) are a Low Impact Development (LID) technology that reduce the total volume of stormwater discharge and peak flows from urban hardscapes. Over time, particulates accumulate in the PICP joints, decreasing the pavement's surface infiltration capacity and negatively affecting its overall functionality. Maintenance with two surface treatment technologies, a hand-held power brush and pressure washer-used in combination with vacuum street sweepers were compared to maintenance with vacuum street sweepers alone at four PICP parking lots. Both surface treatments along with vacuum street sweeping significantly improved the restoration of infiltration capacity for the young (i.e., $<4$ years) PICP section. Pressure washing in combination with vacuum sweeping was effective for PICP sections with larger (13-14 mm) joint openings. Power brushing, however, provided inconsistent results between the PICP sections. The effect of surface treatments was not significant for older (i.e., $>6$ years) installations with small (3-4 mm) joint openings. Though surface treatment resulted in significant improvement with a pressure washer and vacuum street sweeper combination, usage intensity of the parking lot was deemed as an important factor in restoring infiltration capacity. These findings re-emphasize that regular maintenance is essential to ensure long-term hydraulic functionality of PICP.
\end{abstract}

Keywords: clogging; infiltration rate; maintenance; permeable pavements; Permeable Interlocking Concrete Pavers (PICP); restoration; stormwater; urban runoff

\section{Introduction}

Permeable pavements (PP), specifically Permeable Interlocking Concrete Pavements (PICP), are becoming a widely adopted Low Impact Development (LID) technology [1] in Canada and the United States. PICPs are masonry pavers with open joints that are filled with prewashed joint material. PICPs are a better stormwater management alternative in comparison to traditional impermeable pavements as they decrease the effective impervious area (EIA) of a catchment creating opportunities for infiltration and sustaining pre-development hydrologic conditions [2,3]. As an alternative hardscaping material, PICPs mitigate the negative impacts of urbanization by attenuating peak flows, increasing infiltration into the native soil and improving the quality of the water [4]. The potential of permeable pavements to reduce pollutant load to rivers and streams has been demonstrated by several researchers in Canada [5-8], the United States [3,9-13], Europe [2,14-16] and Oceania $[17,18]$. The recognition of benefits has led to the adoption of permeable pavements for low traffic infrastructures like parking lot and sidewalks in the last two decades, and most Canadian and US municipalities use them for source control stormwater management. 
Traditional impervious pavers have either polymeric sand sealed joints or they are laid in cement stabilized base. This results in an overall impervious surface and limits water percolation. In contrast, the joints in between the PICP are filled with a free draining material which aids in water percolation. Stormwater percolates through open joints and voids of permeable pavements to an underlying aggregate base [7], providing a continuous path to enhance surface infiltration. The filtration through the aggregate base improves the quality of the infiltrate [4]. A PICP cross section typically consists of seven distinct components: sub-base, base, bedding layer, joint material, underdrain, geotextile and paver blocks. In PICP, the sub-base, base and bedding layers consist of different size of aggregates which act as a reservoir as well as filtration media for the percolating stormwater.

The hydrologic benefits derived from permeable pavements have been well established in the last two decades by researchers in North America $[6,7,19,20]$. However, researchers have identified that over time the void spaces in permeable pavements become clogged with fines and debris, decreasing the pavement's capacity to infiltrate stormwater [21-24]. Researchers [21-23,25] have tested different equipment for preventive and restorative maintenance of permeable pavements. The most prominent equipment are vacuum and regenerative air street sweepers which are commercially available and utilized by municipalities. Different types of street sweepers include mechanical, regenerative air and vacuum truck [25]. Regenerative air sweeper and vacuum trucks apply suction on the surface to dislodge the dirt from the pavement joints, whereas mechanical sweepers only disperse debris from the surface of the pavement. A vacuum-sweeping truck operates at a speed of $1-3 \mathrm{~km} / \mathrm{h}$ and a maximum power of $2500 \mathrm{rpm}$. It creates suction through a nozzle to remove debris [21]. Regenerative air street sweepers, operating at a similar speed, produce power of $2000 \mathrm{rpm}$ and are equipped with an air recycling system and a wider pickup head. Regenerative air street sweepers are increasingly replacing mechanical street sweepers in municipal fleets because they generate significantly less air pollution and remove finer sediment particles and associated pollutants from pavements.

Baladès et al. (1995), one of the pioneer researchers testing maintenance of permeable pavements, established that regular preventive maintenance is required to maintain the infiltration capacity of old permeable pavements, which can be accomplished by using street sweepers with suction. Restorative maintenance is conducted when the surface infiltration capacity has significantly reduced. Techniques like pressure washing have been effective in removal of fines from the PP joints [22,25]. Gerrits and James (2004) tested removal of material at different depths from the surface of permeable pavements and found maximum restoration of infiltration capacity by removing clogging material up to $15 \mathrm{~mm}$ from the surface. Subsequent removal did not cause a significant increase in the infiltration capacity. This can be achieved by using a standard street sweeping equipment for partial restoration of the infiltration capacity. Gerrits and James (2004) also observed the spatial variability in the infiltration capacity and found it to be lower in areas with high traffic load.

Kumar et al. (2016) observed surface degradation over four years for a parking lot consisting of three different types of permeable pavements with regular preventive maintenance and found that surface infiltration capacity decreased slightly $(2-10 \%)$ throughout the first year. However, significant loss of infiltration capacity (82-90\%) was observed in the subsequent years and more substantial loses in infiltration capacity were associated with high traffic areas like the driveways. The study utilized preventative maintenance by using gentle water spray followed by rotary brush sweeping twice a year which produced substantial benefits as a preventative maintenance practice. Kumar et al. (2016) recommended maintenance of permeable pavements using suction sweeping or pressure washing followed by suction sweeping for the restoration of infiltration capacity. There is, however, a dearth of literature experimenting on restorative maintenance with older PICP parking lots, which are increasingly common across municipalities.

Winston et al. (2016) assessed the effectiveness of different maintenance practices to restore PP surface infiltration capacity on nine permeable pavements (poured and pavers) ranging from 0.5 to 28 years old in North America and Europe using maintenance practices like manual removal of the upper $2 \mathrm{~cm}$ of fill material, mechanical street sweeping, regenerative-air street sweeping, vacuum street 
sweeping, hand-held vacuuming, high pressure washing, and milling of porous asphalt. Winston et al. (2016) concluded that street sweepers using suction action were more effective than mechanical sweepers for PICP maintenance.

The Interlocking Concrete Pavement Institute (ICPI) recommends a minimum infiltration capacity of $250 \mathrm{~mm} / \mathrm{h}$ (Smith 2011) for effective operation of PICP installations. As the use of PICPs increases, practical and effective maintenance practices will become increasingly important. A lack of standardized and proven maintenance techniques inhibits the growth of PICP as a stormwater management practice. Current literature reveals that preventative maintenance helps to preserve the infiltration capacity and reduces the need to adopt restorative maintenance techniques in the long term. However, a lot of old PICP parking lots exist across the Greater Toronto Area which were initially neglected and need restoration of their infiltration capacity. The objective of this study was to evaluate surface treatment technologies including a hand-held power-brush and pressure washer when used in combination with a vacuum-based street sweeper for restoring the infiltration capacity of mature permeable pavement installations and to determine if power brush and/or pressure washer improve the effectiveness of street sweeping. The goal of this work is to develop new restorative maintenance techniques and improve Best Management Practices (BMPs) to restore the hydraulic functionality of mature PICP installations.

\section{Materials and Methods}

\subsection{Field Sites}

The University of Toronto, in collaboration with the Toronto and Region Conservation Authority (TRCA) and Credit Valley Conservation (CVC) in the Greater Toronto Area (GTA), Canada assessed strategies for restorative maintenance on PICP using two surface treatments, a hand-held power brush and a pressure washer, prior to street sweeping in November 2015 and June 2016. The four sections of PICP at two different locations were at different stages of service life and used different PICP product (Table 1).

Table 1. Characteristics of Pavement sections.

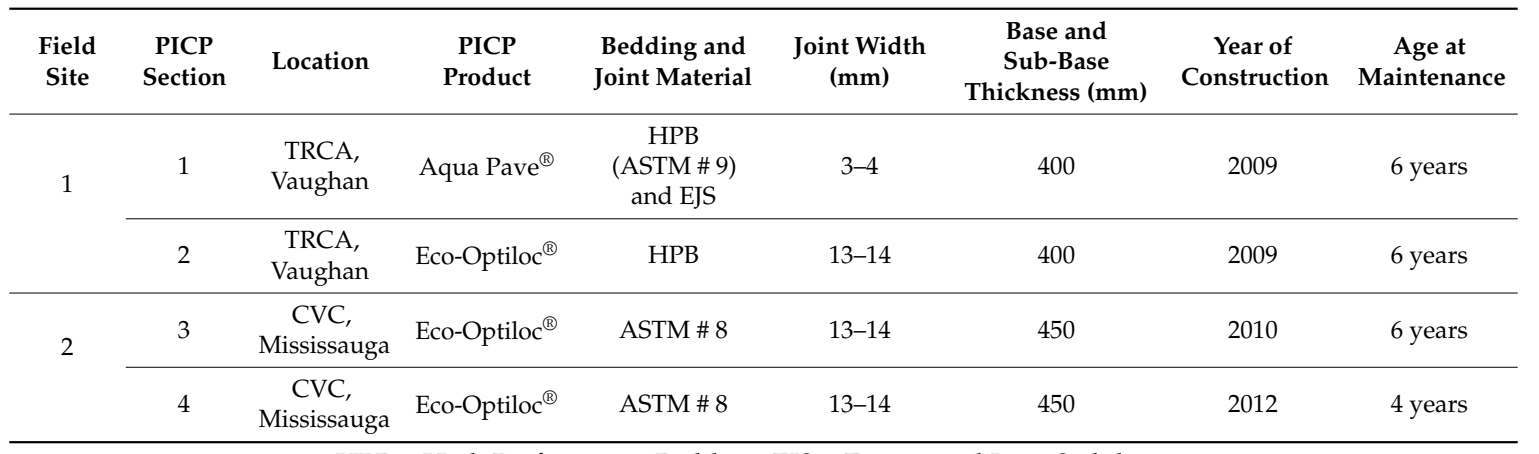

HPB = High Performance Bedding; EJS = Engineered Joint Stabilizer.

Field Site 1 is located at the TRCA's Kortright Centre in Vaughan, Ontario. The parking lot was constructed over the fall of 2009 and the spring of 2010 (Drake et al., 2014) and consists of four isolated sections (one traditional asphalt, two PICP cells (AquaPave ${ }^{\circledR}$ and Eco-Optiloc ${ }^{\circledR}$ ) and one pervious concrete cell). The aerial view of the location and test cells are shown in Figure 1. The total surface area of each section is approx. 230 sqm. The maintenance evaluation was conducted on two PICP sections, marked as PICP 1 and PICP 2 (Figure 1), and one pervious concrete section, marked as PC. Results from the maintenance evaluation of the pervious concrete section is available through a technical brief on the Sustainable Technologies Evaluation Program (STEP) website. This paper deals exclusively with the results of the PICP sections. 


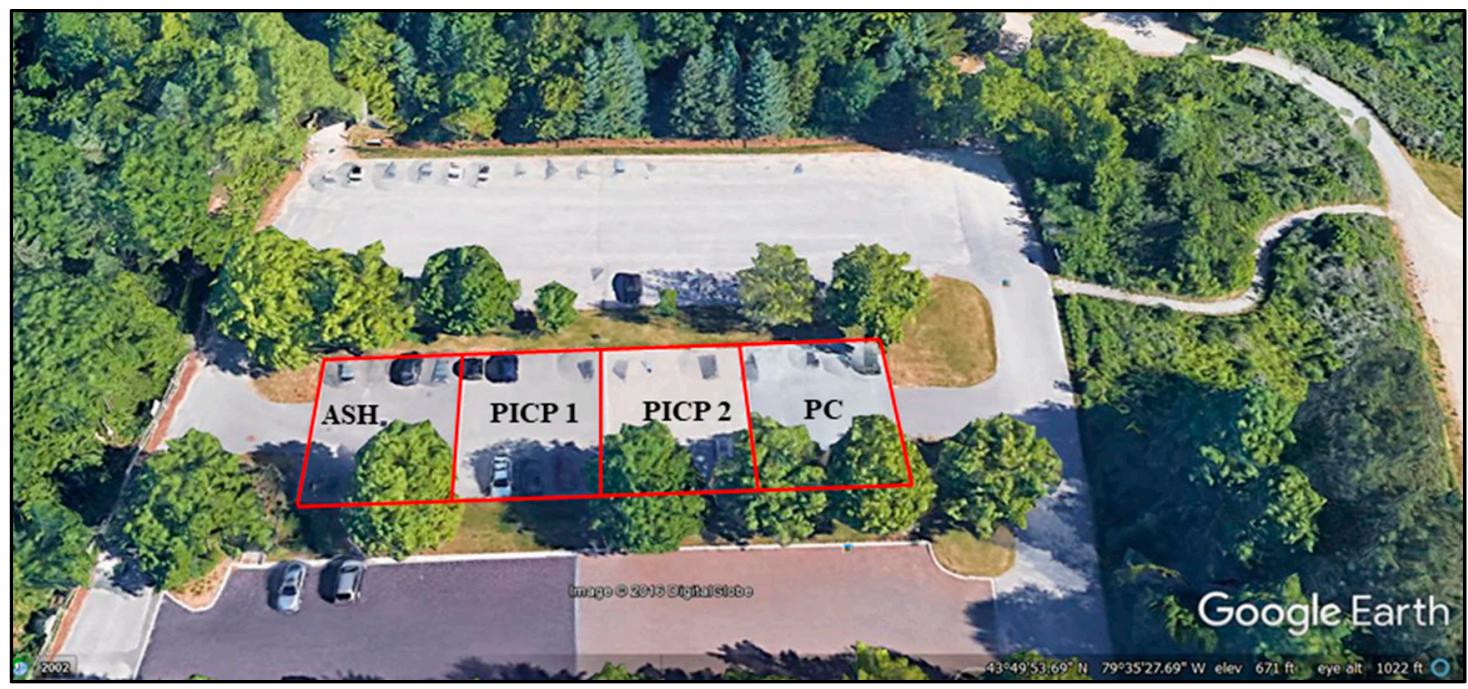

(a)

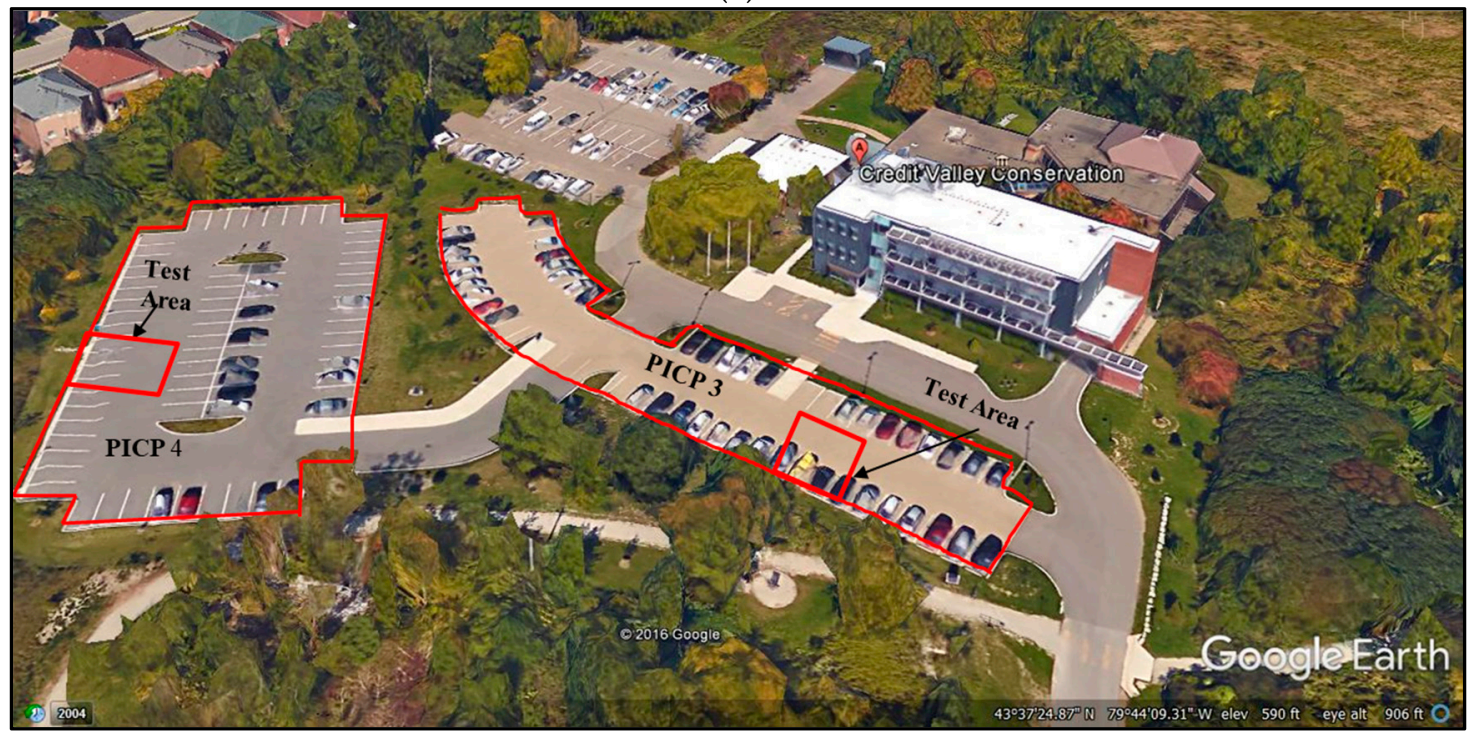

(b)

Figure 1. Field Sites (a) Parking lot at Toronto and Region Conservation Authority (TRCA), Vaughan (b) Credit Valley Conservation (CVC), Mississauga. Mapping Source: Google Earth 2016.

The parking lot at TRCA is an experimental setup initially constructed for evaluation of the hydrologic and water quality benefits of permeable pavements [4,6]. Aggregate base and sub-base layer were constructed of $19 \mathrm{~mm}$ and $50 \mathrm{~mm}$ diameter clear stone for a total depth of $400 \mathrm{~mm}$. PICP 1 is constructed with High Performance Bedding (HPB, ASTM \# 9 aggregate) as the bedding layer and Engineered Joint Stabilizer as the joint material (2-3 mm size) whereas PICP 2 has the HPB as joint and bedding material. PICP 1 also has a geotextile layer placed between the bedding and aggregate layers with an opening size of $0.145 \mathrm{~mm}$ and a mean flow rate of $4800 \mathrm{~L} / \mathrm{min} / \mathrm{m}^{2}$. Both PICP sections include an underdrain. It has a high usage intensity and serves as the parking space for TRCA employees and visitors. A one-time vacuum maintenance with an Elgin-Whirlwind ${ }^{\circledR}$ was completed in 2012 and regular winter maintenance is conducted using a combination of plowing and salting, as needed.

The second field site is the employee parking lot located at the office complex of the Credit Valley Conservation (CVC) in Mississauga, Ontario. Maintenance evaluation was conducted on two sections of the parking lot during May and June 2016. The two parking lots and the test sections are shown in Figure 1. PICP 3 was constructed in 2010; while PICP 4 was constructed in 2012. The total area of the parking lots is $3862 \mathrm{sqm}$, where PICP 3 is $1462 \mathrm{sqm}$ and PICP 4 is $2400 \mathrm{sqm}$. Both the sections were 
constructed with Eco-Optiloc ${ }^{\circledR}$. PICP 3 has $19 \mathrm{~mm}$ clear open recycled concrete for a depth of $450 \mathrm{~mm}$, whereas PICP 4 has $19 \mathrm{~mm}$ clear open recycled concrete for $250 \mathrm{~mm}$ sub-base and $19 \mathrm{~mm}$ clear stone for $200 \mathrm{~mm}$ base. Both the sections use ASTM D 448 Aggregate \# 8 in the bedding layer for the depth of $25 \mathrm{~mm}$ and as the joint material. Both the PICP sections have an underdrain at the bottom. Due to the large size of both of the employee parking lots, small sections were selected, including portions of the parking spots and the driveway to test maintenance strategies. The old parking lot (PICP 3) was vacuumed in 2012 using a vacuum-assisted street sweeper. Winter maintenance at CVC includes a combination of snow plowing and salting. Visual observations at CVC during the time of maintenance evaluation in May and June 2016 indicated that PICP 3, owing to its proximity to the office building, had higher utilization when compared to PICP 4. No separate traffic studies were conducted.

\subsection{Maintenance Equipment}

For surface treatment, a bristle brush (Stihl KB KM46017404905) attached to a motor (Stihl KM130 engine) was used as the power brush, providing a power of approximately $1.4 \mathrm{~kW}$ and a BE pressure washer with a water pressure of 3000 psi was used at two subsections of each PICP test section (Figure 2), while the third subsection was kept as control.

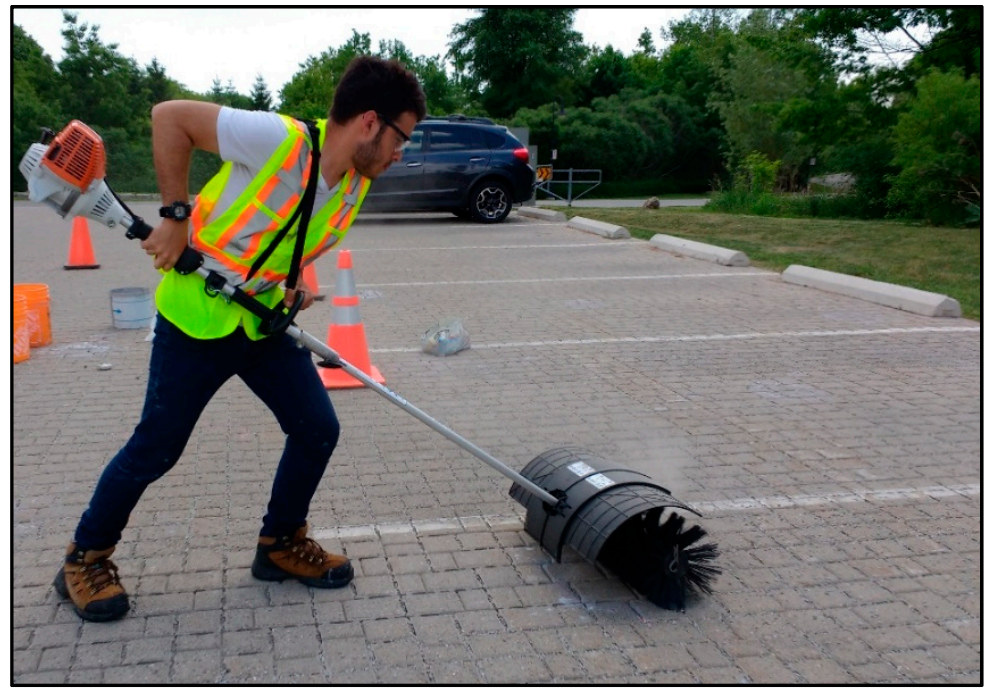

(a)



(b)

Figure 2. Surface Treatment Technologies (a) Power Brush (b) Pressure Wash at CVC, Mississauga.

Two different types of suction-based street sweepers were used at the two field sites due to the availability of equipment. An Elgin Whirlwind ${ }^{\circledR}$ vacuum street sweeper was used for maintenance at Field Site 1 and a TMYCO ${ }^{\circledR}$ DST-6 regenerative air street sweeper was used for street sweeping at Field Site 2. Elgin Whirlwind ${ }^{\circledR}$ creates suction through a 32-inch nozzle and 52-inch sweeping path. TYMCO DST- ${ }^{\circledR}$, on the other hand has a wider 87 -inch pickup head. Air at high pressure is forced from one end of the DST- $6{ }^{\circledR}$ pickup head with the suction head on the other side of the air recycling system. The two types of street sweepers used in this study, along with their cleaning mechanism are shown in Figure 3. 


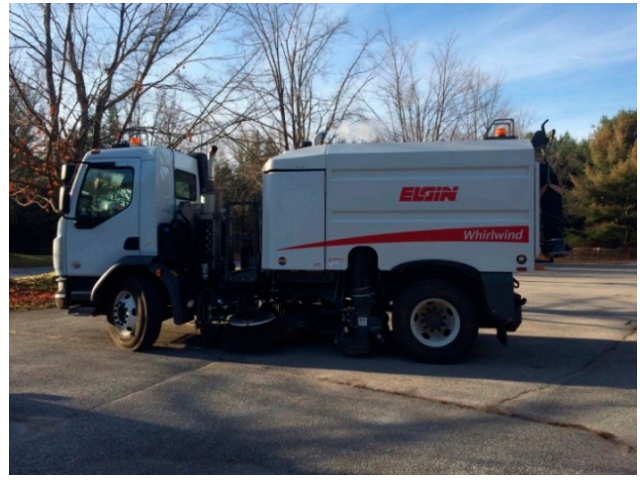

(a)

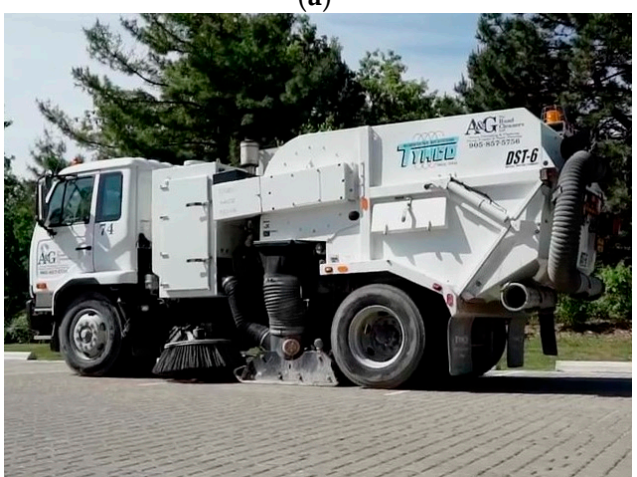

(c)

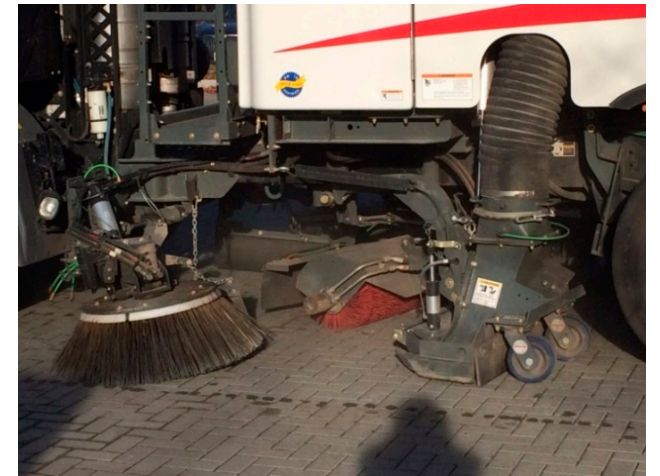

(b)

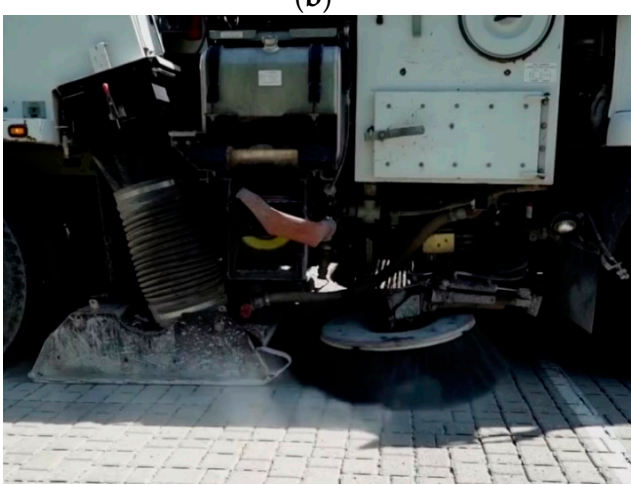

(d)

Figure 3. Street sweeper (a,b) Elgin Whirlwind ${ }^{\circledR}$ Vacuum Street Sweeper with cleaning head (top) (c,d) TYMCO DST- $6{ }^{\circledR}$ Regenerative Air Street Sweeper with cleaning head (bottom).

\subsection{Test Procedure and Data Collection}

At Field Site 1, each PICP section was divided into three subsections (shown in Figure 4) consisting of both side parking spots and the central driveway lane. At Field Site 2, test areas (shown in Figure 1) consisting of three parking spots and an equal area on the adjacent driveway were selected on both PICP 3 and PICP 4 (shown in Figure 5). Figures 4 and 5 also show the schematic of the infiltration testing scheme for PICP 1 and 2 and PICP 3 and 4 respectively. The three subsections were subjected to a different surface treatment, that is, either power brush, pressure wash or no surface treatment. Infiltration measurements were performed before the surface treatment (referred to as pre-maintenance infiltration), followed by the surface treatment chosen and a vacuum street sweeper. A second set of infiltration measurements (referred as post-maintenance infiltration) was performed at the same infiltration test spots points after maintenance. In all, twenty-seven infiltration test spots were selected at PICP 1 and PICP 2 and eighteen test spots were selected at PICP 3 and PICP 4.

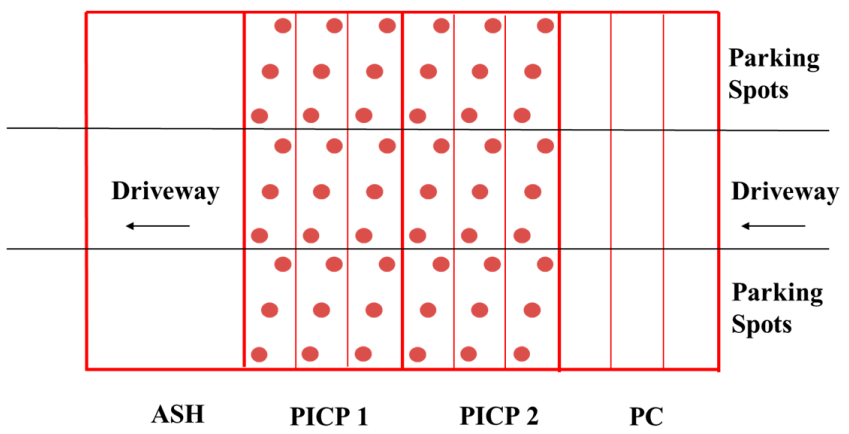

Figure 4. Infiltration testing scheme at permeable interlocking concrete pavement (PICP) 1 and PICP 2. 


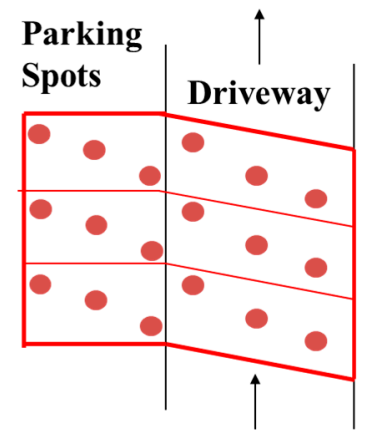

Driveway

Figure 5. Infiltration testing scheme for PICP 3 and PICP 4.

Infiltration measurements were conducted in conformance with ASTM Standard C1781 [26] using single ring infiltration tests (Figure 6). To provide a temporary seal to the pavement surface, modelling clay was used instead of plumber's putty, which is recommended in ASTM Standard C1781. Plumbers putty was found to be less effective in the Ontario climate causing inability to provide a perfect seal. Care was taken to prevent any removal of the joint material during testing by adding water on the paver surface and not on the joints. Since certain PICP sections were heavily clogged a cut-off time of $30 \mathrm{~min}$ was considered at the prewetting stage and of $90 \mathrm{~min}$ during the infiltration test. All the infiltration tests were preceded by a dry period of at least $48 \mathrm{~h}$. As per ASTM standard C1781, the surface infiltration is calculated by:

$$
I=K * M /\left(D^{2} * t\right)
$$

where:

$I=$ Infiltration rate, $\mathrm{mm} / \mathrm{h}$,

$M=$ Mass of infiltrated water, $\mathrm{kg}$,

$D=$ Inside diameter of infiltration ring, $\mathrm{mm}$,

$t=$ Time required for measured amount of water to infiltrate the surface, $\mathrm{s}$, and

$K=4,583,666,000$ in SI units.

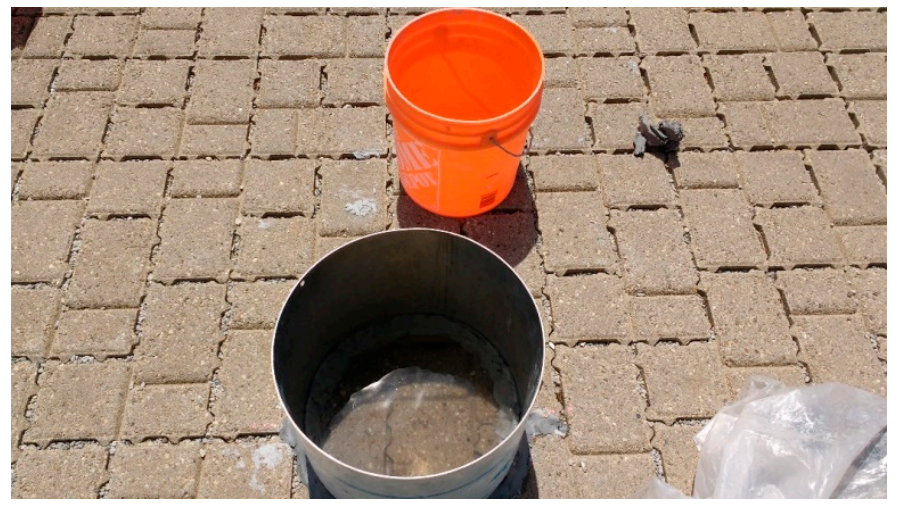

Figure 6. Standing water during a failed Infiltration test at CVC, Mississauga, Canada.

Infiltration rings had slightly different diameter. Based on the cut-off time of 30 min during pre-wetting and of $90 \mathrm{~min}$ for the infiltration test, depending on the failure stage and the ring used during testing, the minimum detection limit (MDL) or censoring limits adopted for the failed infiltration tests are summarized in Table 2. 
Table 2. Minimum Detection Limit.

\begin{tabular}{cccc}
\hline \multicolumn{4}{c}{ Infiltration Rate Detection Limit } \\
\hline \multirow{2}{*}{ Ring Number } & Diameter $(\mathbf{m m})$ & Minimum Infiltration Rate $\mathbf{( m m} / \mathbf{h})$ \\
\cline { 3 - 4 } & & Pre-Wetting & Final Test \\
\hline 1 & 318 & 91 & 30 \\
2 & 298 & 103 & 34 \\
3 & 278 & 119 & 40 \\
\hline
\end{tabular}

\subsection{Data Analysis}

More than half of the pre-maintenance infiltration measurements consisted of censored observations, that is, below the detection limit of the infiltration tests (Table 2). Post-maintenance, only $32 \%$ of the infiltration data was censored. Analysis for censored datasets was completed following recommended practices as outlined by Helsel (2005). Statistical analyses were completed in R project version 3.3.1. The R package for Non detects and Data Analysis (NADA), authored and maintained by Lee and Helsel [27], was utilized for the analyses. Datasets for each PICP section and subsection had varying degrees of censored observations. Descriptive statistics were computed using the non-parametric Kaplan-Meier (KM) method when median values could be estimated with certainty, that is, when censoring percentage was less than 50\% [28]. KM method stems from medical sciences statistical analysis for survival data (which is typically right censored) and has been adapted for left censored environmental data in NADA. NADA internally flips the dataset to make the data right censored, which can then be analyzed by the KM method. The probability function estimates are calculated for each observation and the results are re-transformed to ascertain the descriptive statistics. When censored data exceeded 50\%, robust Regression of Order Statistics (ROS) was completed. ROS in NADA is a non-parametric method that uses Weibull plotting positions of uncensored and censored observations to calculate the normal score by performing a regression of the uncensored observations and their normal quantiles [28]. It uses this model to estimate censored observations. Subsequently, it uses both the censored and uncensored values to estimate the summary statistics [28].

A generalized Wilcoxon test was used to assess differences between infiltration capacity before and after maintenance as well as to assess the effectiveness of individual surface treatments. Two-sided tests were used when the anticipated direction of change between two groups was unknown and one-sided tests were used when the anticipated direction of change was known. Due to the high level of uncertainty and spatial variability between test spots and pavement subsections both $5 \%$ and $10 \%$ significance levels were considered. Surface treatments at each site were evaluated sequentially by two-sided Wilcoxon test to assess the pre-maintenance similarity of the pavement subsections. One-sided Wilcoxon test was used to compare the significance of difference between post maintenance surface treatments and control subsections and two-sided Wilcoxon tests was used to compare the surface treatment types (i.e., pressure washing and power brush). Finally, an overall comparison was conducted between pre and post-maintenance infiltration testing for each surface treatment subsection, parking spots and driveways sections.

\section{Results and Discussion}

\subsection{Descriptive Statistics}

Maintenance using different surface treatments along with a vacuum street sweeper was evaluated for four PICP sections of two parking lots in the Greater Toronto Area. In total 180 infiltration tests were completed at all four PICP sections. The overall descriptive statistics are summarized in Tables 3 and 4 summarizes the descriptive statistics by each surface treatment type. A total of 45 observations of the 90 pre-maintenance infiltration measurements were censored. The total number of censored observations decreased to 29 during post-maintenance infiltration tests. Individually, PICP 1 , that is, 
the AquaPave ${ }^{\circledR}$ section at TRCA, was heavily clogged than the other sections and had approximately $70 \%$ and 59\% censored observations during pre and post-maintenance, respectively. PICP 4 was a relatively less-utilized and newer parking lot at CVC, had no censored observations. After maintenance, the median infiltration capacity for PICP 1, PICP 2 and PICP 4 increased by 19-62\%. At PICP 3 the median infiltration capacity increased by approximately $670 \%$ (13-folds) with a huge decline in the censored observations from ten (out of 18) to only one observation.

Table 3. Overall Descriptive Statistics.

\begin{tabular}{|c|c|c|c|c|c|c|c|}
\hline Section & $\begin{array}{l}\text { Tests } \\
\text { Stage }\end{array}$ & $\begin{array}{l}\text { Number } \\
\text { of Tests }\end{array}$ & $\begin{array}{c}\text { Percent } \\
\text { Censored }(\%)\end{array}$ & $\begin{array}{l}\text { Min. Infiltration/MDL } \\
(\mathrm{mm} / \mathrm{h})\end{array}$ & $\begin{array}{l}\text { Max Infiltration } \\
(\mathrm{mm} / \mathrm{h})\end{array}$ & $\begin{array}{l}\text { Median } \\
(\mathrm{mm} / \mathrm{h})\end{array}$ & $\begin{array}{l}\text { Standard } \\
\text { Deviation }\end{array}$ \\
\hline PICP 1 & Pre & 27 & 70 & 30 & 180 & 60 & 40 \\
\hline \multirow{2}{*}{ PICP 2} & Pre & 27 & 59 & 30 & 450 & 70 & 100 \\
\hline & Post & 27 & 44 & 70 & 6980 & 90 & 1650 \\
\hline \multirow{2}{*}{ PICP 4} & Pre & 18 & - & 320 & 4770 & 1610 & 1130 \\
\hline & Post & 18 & - & 770 & 8690 & 2600 & 2310 \\
\hline
\end{tabular}

Pre = Pre-Maintenance Infiltration, Post = Post-Maintenance Infiltration.

Table 4. Descriptive Statistics for each site by surface treatment.

\begin{tabular}{|c|c|c|c|c|c|c|}
\hline Section & $\begin{array}{c}\text { Surface } \\
\text { Treatment }\end{array}$ & Test Stage & $\begin{array}{l}\text { Number of } \\
\text { Tests }\end{array}$ & $\begin{array}{c}\text { Percent } \\
\text { Censored (\%) }\end{array}$ & $\begin{array}{l}\text { Median } \\
(\mathrm{mm} / \mathrm{h})\end{array}$ & $\begin{array}{r}\text { Standard } \\
\text { Deviation }\end{array}$ \\
\hline \multirow{6}{*}{ PICP 1} & \multirow[b]{2}{*}{$\mathrm{CT}$} & Pre & 9 & 89 & NA & NA \\
\hline & & Post & 9 & 78 & 50 & 70 \\
\hline & \multirow{2}{*}{ PW } & Pre & 9 & 67 & 50 & 40 \\
\hline & & Post & 9 & 56 & 80 & 40 \\
\hline & \multirow{2}{*}{ PB } & Pre & 9 & 56 & 70 & 40 \\
\hline & & Post & 9 & 44 & 90 & 470 \\
\hline \multirow{6}{*}{ PICP 2} & \multirow[b]{2}{*}{$\mathrm{CT}$} & Pre & 9 & 56 & 80 & 150 \\
\hline & & Post & 9 & 44 & 90 & 860 \\
\hline & \multirow{2}{*}{ PW } & Pre & 9 & 56 & 70 & 30 \\
\hline & & Post & 9 & 33 & 450 & 2620 \\
\hline & \multirow{2}{*}{$\mathrm{PB}$} & Pre & 9 & 67 & 60 & 100 \\
\hline & & Post & 9 & 56 & 160 & 480 \\
\hline \multirow{6}{*}{ PICP 3} & \multirow{2}{*}{$\mathrm{CT}$} & Pre & 6 & 67 & 50 & 20 \\
\hline & & Post & 6 & 0 & 180 & 1300 \\
\hline & \multirow{2}{*}{ PW } & Pre & 6 & 50 & 50 & 290 \\
\hline & & Post & 6 & 0 & 1290 & 1710 \\
\hline & \multirow{2}{*}{$\mathrm{PB}$} & Pre & 6 & 50 & 40 & 240 \\
\hline & & Post & 6 & 17 & 620 & 1230 \\
\hline \multirow{6}{*}{ PICP 4} & \multirow{2}{*}{$\mathrm{CT}$} & Pre & 6 & 0 & 770 & 900 \\
\hline & & Post & 6 & 0 & 1170 & 770 \\
\hline & \multirow{2}{*}{ PW } & Pre & 6 & 0 & 1770 & 880 \\
\hline & & Post & 6 & 0 & 2600 & 1460 \\
\hline & \multirow[b]{2}{*}{$\mathrm{PB}$} & Pre & 6 & 0 & 1350 & 1550 \\
\hline & & Post & 6 & 0 & 2860 & 3220 \\
\hline
\end{tabular}

Pre = Pre-Maintenance Infiltration; Post $=$ Post-Maintenance Infiltration; CT = Control; PW = Pressure Wash; $\mathrm{PB}=$ Power Brush.

\subsection{Pre-Maintenance Site Evaluation}

Before comparing the effect of surface treatments during post maintenance infiltration tests, it was important to evaluate the similarity of subsections to ascertain whether a considerable difference existed between them prior to maintenance. Table 5 summarizes the overall significance of difference of two-sided generalized Wilcoxon test for surface treatment sub-sections before any maintenance. Table 6 indicates the results of significance of difference of two-sided generalized Wilcoxon test for 
differences between any two subsections. The results in Tables 5 and 6 indicate that no significant difference existed between subsections prior to the maintenance evaluation.

Table 5. Overall significance of difference for two-sided generalized Wilcoxon test during Pre-Maintenance.

\begin{tabular}{cc}
\hline Section & $\begin{array}{c}\text { Pre-Maintenance Infiltration } \\
\boldsymbol{p} \text {-Value }\end{array}$ \\
\hline PICP 1 & 0.58 \\
PICP 2 & 0.69 \\
PICP 3 & 0.33 \\
PICP 4 & 0.40 \\
\hline
\end{tabular}

Table 6. Significance of difference for two-sided generalized Wilcoxon test between each subsection.

\begin{tabular}{|c|c|c|c|c|c|c|c|}
\hline \multirow{2}{*}{ Section } & \multicolumn{3}{|c|}{ Pre-Maintenance Infiltration } & \multirow{2}{*}{ Section } & \multicolumn{3}{|c|}{ Pre-Maintenance Infiltration } \\
\hline & \multicolumn{3}{|c|}{$p$-Value } & & \multicolumn{3}{|c|}{$p$-Value } \\
\hline \multirow{3}{*}{ PICP 1} & & PB & $\mathrm{PW}$ & \multirow{3}{*}{ PICP 3} & & PB & PW \\
\hline & CT & 0.42 & 0.24 & & CT & 0.56 & 0.14 \\
\hline & PB & - & 0.86 & & $\mathrm{~PB}$ & - & 0.44 \\
\hline \multirow{3}{*}{ PICP 2} & & PB & PW & \multirow{3}{*}{ PICP 4} & & PB & PW \\
\hline & CT & 0.81 & 0.41 & & CT & 0.20 & 0.26 \\
\hline & PB & - & 0.47 & & PB & - & 0.88 \\
\hline
\end{tabular}

$\mathrm{CT}=$ Control; $\mathrm{PW}=$ Pressure Wash; $\mathrm{PB}=$ Power Brush.

\subsection{Overall Effect of Maintenance}

A comparison of the pre and post-maintenance infiltration was conducted to determine the overall effect of maintenance for each PICP section. The results of the generalized Wilcoxon one-sided test for significance of difference between the pre and post-maintenance infiltration capacity are summarized in Table 7. Figure 7 shows censored box plots for all the sections illustrating the overall change in infiltration capacity because of maintenance.

Pre-cleaning of the clogged joint space had a positive impact on restoration of the infiltration capacity. All PICP sections demonstrated a significant increase in the post-maintenance infiltration capacity when compared with the pre-maintenance infiltration capacity. On evaluating the overall effect of maintenance in conjunction with the descriptive statistics in Table 3, the maximum post-maintenance infiltration rate for PICP 1 reached $1441 \mathrm{~mm} / \mathrm{h}$ which was approximately a fifth of the maximum infiltration rate of PICP 2 which was of same age but has a joint opening of approximately 13-14 mm, compared to only 3-4 mm for PICP 1. PICP 3 and PICP 4 also demonstrated an increase in their post-maintenance infiltration capacity. The low usage intensity of PICP 4 and a high infiltration capacity before maintenance indicates less clogging of the test site. For PICP 4 , the maximum post-maintenance infiltration rate reached approximately $8000 \mathrm{~mm} / \mathrm{h}$, which was higher than the maximum post-maintenance infiltration rate for PICP 3. These observations presented an interesting finding that overall restorative maintenance might be a useful alternative for pavers with large joint openings and has a greater impact when conducted out early in the life of the PICP installation, like for PICP 4.

Table 7. Results of generalized Wilcoxon test for difference between pre and post-maintenance infiltration.

\begin{tabular}{cccc}
\hline Section & $\boldsymbol{p}$-Value & Significant at $\mathbf{5 \%}$ & Significant at $\mathbf{1 0} \%$ \\
\hline PICP 1 & $7 \times 10^{-2}$ & No & Yes \\
PICP 2 & $8 \times 10^{-3}$ & Yes & Yes \\
PICP 3 & $4.3 \times 10^{-6}$ & Yes & Yes \\
PICP 4 & $9.5 \times 10^{-3}$ & Yes & Yes \\
\hline
\end{tabular}


PICP 1

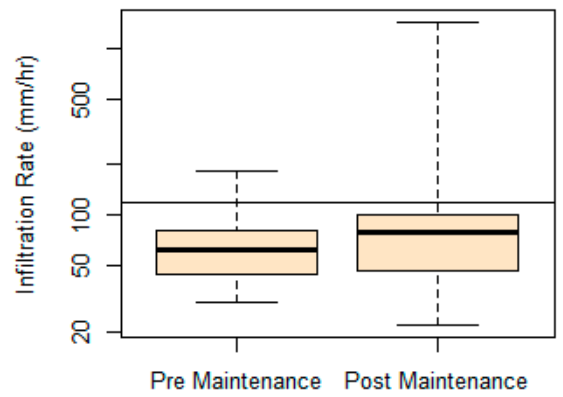

PICP 3

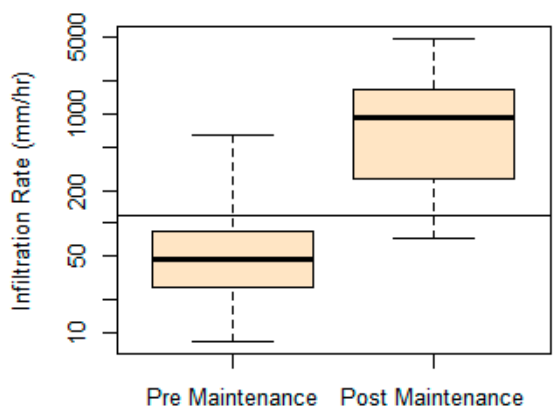

PICP 2

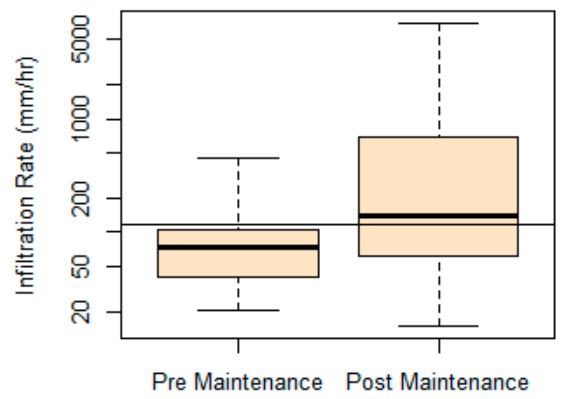

PICP 4

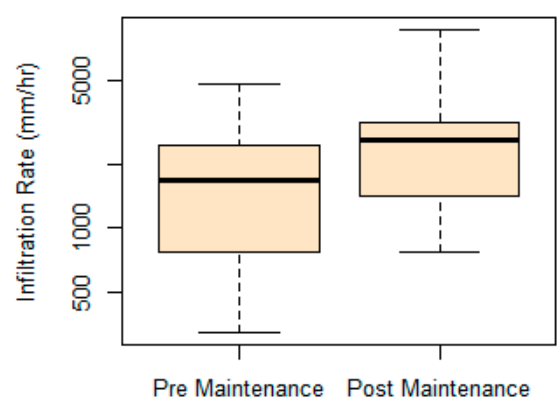

Figure 7. Censored Box plot for PICP sections. Note: The horizonal line in the box plots represents the highest minimum detection limit (MDL) of the dataset with multiple censoring limits. Kaplan-Meier (KM) percentiles are plotted for values below the detection limit.

\subsection{Effect of Maintenance Combined with Surface Treatment}

A comparison of pre and post-maintenance infiltration capacity was conducted for each PICP section to determine the significance of change for each surface treatment. The results of intergroup comparison of the cumulative distribution function using the one-sided significance ( $p$-value) results of generalized Wilcoxon test are presented in Table 8 . Figure 8 shows the boxplots for the censored data illustrating the change in infiltration capacity for each surface treatment. For PICP 1, there was no significant increase in the infiltration capacity for any surface treatment. The authors attribute this result to the fact it was a comparatively older parking lot with small joint stabilizing aggregate and joint openings of about 3-4 mm wide. Although the permeable pavements were de-iced with salt only during the winter, the surrounding areas received a salt-sand mix, which increased the amount of sediment tracked onto the lot relative to the PICP 3 and PICP 4 sites, which utilized salt only across the entire property. The joints were heavily clogged with the dirt embedded itself deep into the joint space. For PICP 2, with its large joint openings, power washing was able to dislodge the dirt from PICP joints which was captured by the vacuum street sweeper. PICP 3 and PICP 4 demonstrated a significant increase in infiltration capacity for all surface treatments. Overall, the pressure washer used in conjunction with vacuum sweeping was found to result in a significant increase in surface infiltration capacity for PICP 2, 3 and 4 . The power brush used in conjunction with vacuum sweeping was found to be effective in both PICP 3 and PICP 4 (Field Site 2) but not in PICP 2 (Field Site 1). 



Figure 8. Boxplots for each surface treatment. Note: The horizonal line in the box plots represents the highest MDL of the dataset with multiple censoring limits. KM percentiles are plotted for values below the detection limit. CT: Control; PW: Pressure Wash; PB: Power Brush. 
Table 8. Results of one-sided generalized Wilcoxon test for effect of each surface treatment.

\begin{tabular}{|c|c|c|c|c|}
\hline Section & Surface Treatment & $p$-Value & Significant at $5 \%$ & Significant at $10 \%$ \\
\hline \multirow{3}{*}{ PICP 1} & $\mathrm{CT}$ & 0.37 & No & No \\
\hline & PB & 0.09 & No & Yes \\
\hline & PW & 0.23 & No & No \\
\hline \multirow{3}{*}{ PICP 2} & $\mathrm{CT}$ & 0.24 & No & No \\
\hline & PB & 0.14 & No & No \\
\hline & PW & 0.03 & Yes & Yes \\
\hline \multirow{3}{*}{ PICP 3} & $\mathrm{CT}$ & 0.00 & Yes & Yes \\
\hline & PB & 0.01 & Yes & Yes \\
\hline & PW & 0.01 & Yes & Yes \\
\hline \multirow{3}{*}{ PICP 4} & CT & 0.26 & No & No \\
\hline & PB & 0.04 & Yes & Yes \\
\hline & PW & 0.04 & Yes & Yes \\
\hline
\end{tabular}

$\mathrm{CT}=$ Control; $\mathrm{PW}=$ Pressure Wash; $\mathrm{PB}=$ Power Brush.

\subsection{Comparing Surface Treatments}

Pre-maintenance site infiltration measurements indicated that the pavement subsections were similar before receiving any surface treatment. Post-maintenance infiltration test spots were compared to the control (i.e., PW and PB with CT) to determine if the pavement's infiltration capacity differed because of the tested surface treatments. One-sided generalized Wilcoxon test was used to test for significant difference between control and surface treatment (PB and PW) subsections. A two-sided generalized Wilcoxon test was conducted to determine if one surface treatment (PB or PW) outperformed the other. Table 9 summarizes the overall statistical significance of differences between the cumulative distribution function between post-maintenance pavement subsections while Table 10 summarizes the statistical significance of differences between individual maintenance strategies. Overall, for PICP 1, the pavement subsections were not significantly different from each other post-maintenance but individually, the power brushing surface treatment was found to slight improve the pavement infiltration capacity more than the control (i.e., vacuum-sweeping only). Power washing was not found to provide any significant benefit for restoring surface infiltration capacity at PICP 1. For PICP 2 and PICP 3, there was no statistically significant difference between the pavement subsection post-maintenance in comparison to the control section (Tables 9 and 10). This implies that although there was an improvement because of maintenance, the maintenance strategy or the combination of strategies did not significantly influence outcomes. PICP 4 demonstrated significant difference between the post-maintenance pavement subsections infiltration capacity. PICP 4 was less clogged than PICP 1, 2 and 3, and was also the youngest pavement evaluated. Moreover, PICP 4 was subjected to traffic only when the parking lots closer to the office buildings were occupied. Therefore, it was not surprising that the surface was less clogged relative to the other evaluated pavements. Both the power brush and pressure washer were helpful in dislodging the sediments and provided significantly more surface restoration than vacuum sweeping alone.

Table 9. Overall Inter group significance of difference of the two-sided generalized Wilcoxon test.

\begin{tabular}{cc}
\hline Section & Post-Maintenance Infiltration \\
\hline PICP 1 & 0.16 \\
PICP 2 & 0.64 \\
PICP 3 & 0.60 \\
PICP 4 & 0.04 \\
\hline
\end{tabular}


Table 10. Inter group significance of difference (GW test) between surface treatment spots.

\begin{tabular}{|c|c|c|c|c|c|c|c|}
\hline \multirow{2}{*}{ Section } & \multicolumn{3}{|c|}{ Post-Maintenance Infiltration } & \multirow{2}{*}{ Section } & \multicolumn{3}{|c|}{ Post-Maintenance Infiltration } \\
\hline & \multicolumn{3}{|c|}{$p$-Value } & & \multicolumn{3}{|c|}{$p$-Value } \\
\hline \multirow{3}{*}{ PICP 1} & & PB & PW & & & PB & PW \\
\hline & $\mathrm{CT}$ & 0.04 & 0.09 & PICP 3 & $\mathrm{CT}$ & 0.24 & 0.17 \\
\hline & $\mathrm{PB}$ & & 0.43 * & & PB & & 0.75 * \\
\hline \multirow{3}{*}{ PICP 2} & & PB & PW & & & PB & PW \\
\hline & $\mathrm{CT}$ & 0.39 & 0.22 & PICP 4 & $\mathrm{CT}$ & 0.02 & 0.01 \\
\hline & $\mathrm{PB}$ & & 0.37 * & & PB & & $0.43^{*}$ \\
\hline
\end{tabular}

$\mathrm{CT}=$ Control; PW = Pressure Wash; $\mathrm{PB}=$ Power Brush; ${ }^{*}=$ two-sided test.

\subsection{Spatial Variability and Difference in Usage Characteristics}

A final comparison was conducted to evaluate the effect of maintenance on areas with different usage characteristics, that is, parking lots and driveways. Spatial variability is illustrated through a contour map generated in ArcGIS 10.4.1 using the Inverse Distance Weighing method. Figure 9 presents the spatial variability at PICP 1 and PICP 2 (Field Site 1), whereas Figure 10 provides the spatial variability at PICP 3 and PICP 4 (Field Site 2) at both pre and post-maintenance. Most of the parking spot sections had higher surface infiltration capacities than the adjacent sections on the driveway emphasizing the fact that usage intensity also influences the surface degradation and maintenance requirements for PICP.

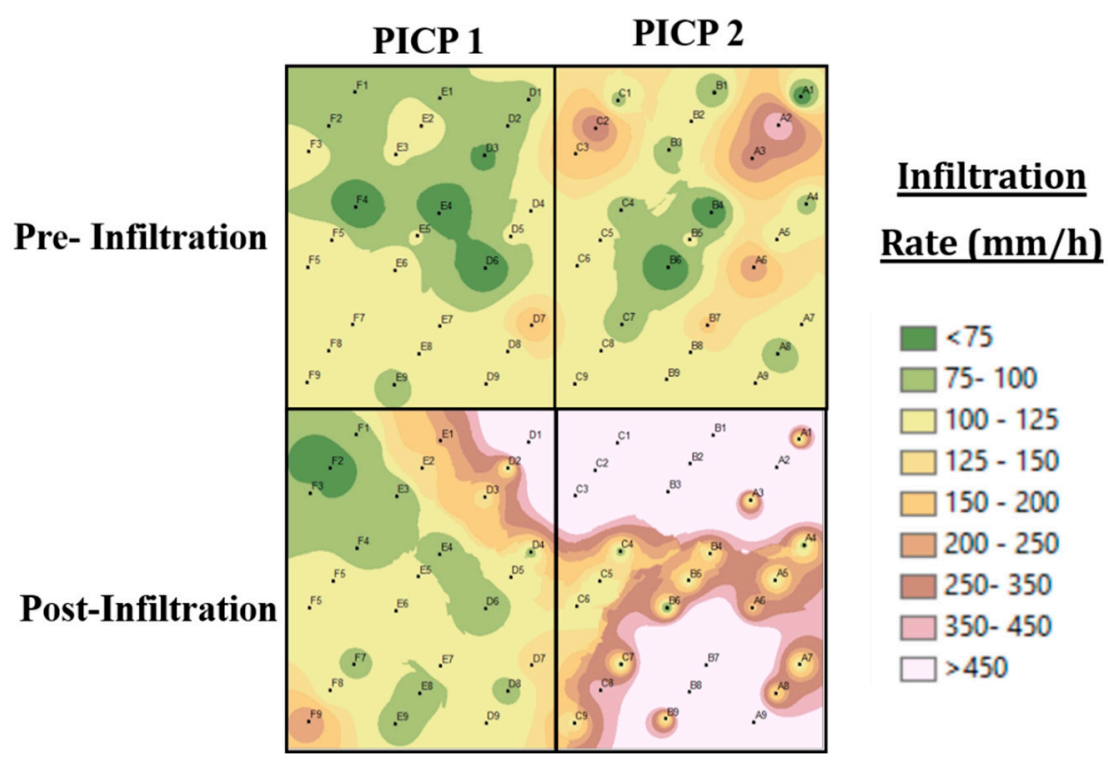

Figure 9. Spatial Variability of Infiltration Capacity at Field Site 1. 


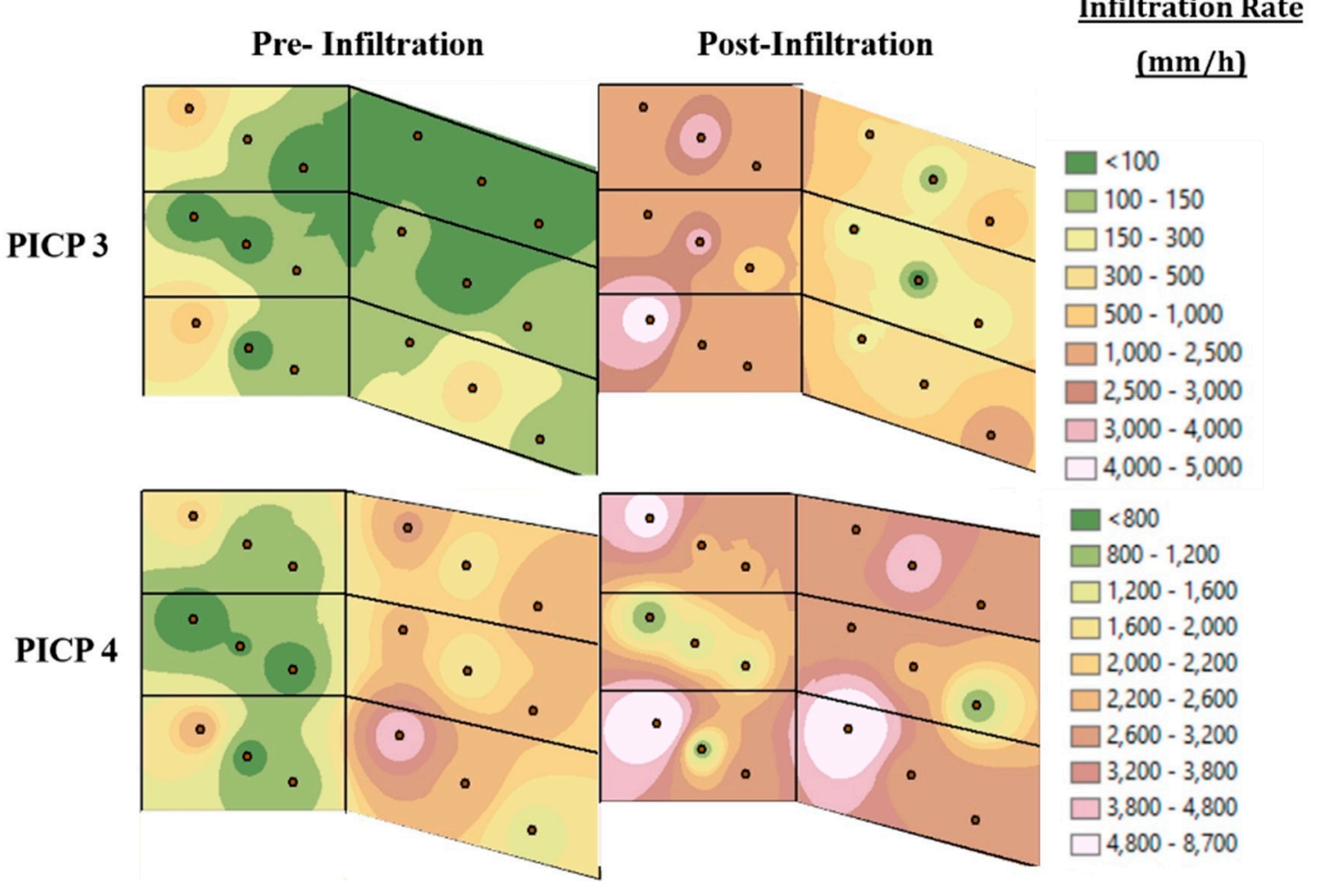

Figure 10. Spatial Variability of Infiltration Capacity at Field Site 2.

The usage intensity observed in driveways was more than the parking spots with continuous inflow and outflow of vehicles looking for parking space. These areas were more prone to receiving fines and debris in comparison to the parking spots. The significance results of generalized Wilcoxon one-sided tests are presented in Table 11 comparing the pre and post maintenance infiltration rates at both parking spots and driveways. Overall, it was observed that effect of maintenance was significant for all the parking spots. The effect of maintenance was significant driveway section of PICP 2 only. The results in Table 11 reemphasize that high usage intensity areas require frequent preventive maintenance. Restoration of infiltration capacity was possible for wider joint spaced and highly used PICP 2 and 3. The change in infiltration capacity was not significant for PICP 4 as the infiltration capacity was very high during the pre-maintenance stage.

Table 11. Comparison of different pavement usage characteristics.

\begin{tabular}{ccccc}
\hline Section & Surface Treatment & $p$-Value & Significant at $\mathbf{5 \%}$ & Significant at $\mathbf{1 0} \%$ \\
\hline \multirow{2}{*}{ PICP 1} & Driveway & 0.47 & No & No \\
& Parking spots & $9 \times 10^{-4}$ & Yes & Yes \\
\hline \multirow{2}{*}{ PICP 2 } & Driveway & $4 \times 10^{-3}$ & Yes & Yes \\
& Parking spots & $9 \times 10^{-5}$ & Yes & Yes \\
\hline \multirow{2}{*}{ PICP 3 } & Driveway & $7 \times 10^{-2}$ & No & Yes \\
& Parking spots & $8 \times 10^{-3}$ & Yes & Yes \\
\hline \multirow{2}{*}{ PICP 4 } & Driveway & $2 \times 10^{-1}$ & No & No \\
& Parking spots & $7 \times 10^{-2}$ & No & Yes \\
\hline
\end{tabular}

\section{Conclusions}

Permeable interlocking concrete pavements (PICP) have been recognized as an effective stormwater management practice. However, over time, the joint spaces which allow stormwater to infiltrate through the pavement surface become clogged with fines and sediments. Effective maintenance technologies, both preventive and restorative, are required to maintain or rejuvenate 
the hydrologic benefits of aging permeable pavements. This study investigated whether using the surface treatments in combination with vacuum-based street sweeping provided significant benefits over using only street sweepers.

Surface treatments with the power brush and pressure washer made it easier for the vacuum action of the street sweeper at newer installations to remove joint material with less usage intensity. Pavement age, joint space and usage intensity greatly influenced the overall effectiveness of all maintenance combinations. A mature PICP section, PICP 1, with small joint spacing was heavily clogged and effective restorative maintenance could not be achieved. This section was similar in pavement structure, that is, base and sub-base, to PICP 2 with difference in joint opening size due to difference in product and placement of a geotextile layer. Mature pavement sections, PICP 2 and 3 with larger joint openings, demonstrated some improvement with pressure washing followed by vacuum-based street sweeping. Substantial improvement in infiltration capacity was achieved for the newer PICP section, PICP 4, that was not subjected to intense traffic loads. Overall pressure wash with vacuum sweeping was shown to be an effective approach for rejuvenating PICP sections with larger joint space. Power brush showed some improvement in infiltration capacity, but the results were inconsistent as significant sections of the pavements remained clogged. The median infiltration capacity for the least clogged section, PICP 4 , improved by $62 \%$ and the highest infiltration capacity was measured as $8700 \mathrm{~mm} / \mathrm{h}$. For mature parking lots, that is, PICP 1, maintenance resulted in an increase in infiltration rate to $80 \mathrm{~mm} / \mathrm{h}$ which is well below the $250 \mathrm{~mm} / \mathrm{h}$ recommended minimum infiltration rate by ICPI (Smith 2011). Thus, it is recommended that a combination of pressure washing along with vacuum sweeping, adopted earlier in the pavement life, would help in maintaining high levels of infiltration.

Author Contributions: Software, formal analysis, validation, investigation and writing the first draft was completed by K.S. Conceptualization, methodology, writing review and editing was completed by J.D. and T.V.S. J.D. also provided supervision to K.S. during the project. W.K.V.L. helped with Project administration at CVC and writing review and editing.

Funding: Research funding was supported by the NSERC Discovery Grant and the Great Lakes Sustainability Fund. Funding to TRCA and CVC is provided by the regional partners the City of Toronto, the City of Mississauga, the Region of Peel and York Region. Funding for the PhD candidate was provided by Natural Sciences and Engineering Research Council (NSERC) and Canada Masonry Design Center (CMDC).

Acknowledgments: The authors would like to thank Toronto and Region Conservation Authority (TRCA) and Credit Valley Conservation (CVC) and their staff for their continued support during the experimentation schedule. Streetsweepers were provided by the City of Toronto and City of Mississauga. Undergrad student research assistants played an important part in assisting with the field work during the maintenance testing. Special thanks to Johan Carlos, Wai Lam and Gordon Wong for their assistance. Thanks to Alex Fitzgerald for coordination during evaluation at CVC.

Conflicts of Interest: The authors declare no conflict of interest.

\section{References}

1. Interlocking Concrete Pavement Institute (ICPI). Annual Report; ICPI: Chantilly, VA, USA, 2016.

2. Pratt, C.J.; Mantle, J.D.G.; Schofield, P.A. Urban Stormwater Reduction and Quality Improvement through the Use of Permeable Pavements. Water Sci. Technol. 1989, 21, 769-778. [CrossRef]

3. Yang, B.; Li, S. Green Infrastructure Design for Stormwater Runoff and Water Quality: Empirical Evidence from Large Watershed-Scale Community Developments. Water 2013, 5, 2038-2057. [CrossRef]

4. Drake, J.; Bradford, A.; Van Seters, T. Winter Effluent Quality from Partial-Infiltration Permeable Pavement Systems. J. Environ. Eng. 2014, 140, 04014036. [CrossRef]

5. Crookes, A.J.; Drake, J.A.P.; Green, M. Hydrologic and Quality Control Performance of Zero-Exfiltration Pervious Concrete Pavement in Ontario. J. Sustain. Water Built Environ. 2017, 3, 1-8. [CrossRef]

6. Drake, J.; Bradford, A.; Van Seters, T. Hydrologic Performance of Three Partial-Infiltration Permeable Pavements in a Cold Climate over Low Permeability Soil. J. Hydrol. Eng. 2014, 19, 04014016. [CrossRef]

7. Huang, J.; Valeo, C.; He, J.; Chu, A. Winter Performance of Inter-Locking Pavers-Stormwater Quantity and Quality. Water 2012, 4, 995-1008. [CrossRef] 
8. Gerrits, C.; James, W. Restoration of Infiltration Capacity of Permeable Pavers. In Global Solutions for Urban Drainage; American Society of Civil Engineers: Reston, VA, USA, 2004; pp. 1-16.

9. Booth, D.B.; Leavitt, J. Field Evaluation of Pavement Systems for Improved Stormwater Management. J. Am. Plan. Assoc. 1999, 65, 314-325. [CrossRef]

10. Brattebo, B.O.; Booth, D.B. Long-Term Stormwater Quantity and Quality Performance of Permeable Pavement Systems. Water Res. 2003, 37, 4369-4376. [CrossRef]

11. Dietz, M.E.; Clausen, J.C. Stormwater Runoff and Export Changes with Development in a Traditional and Low Impact Subdivision. J. Environ. Manag. 2008, 87, 560-566. [CrossRef] [PubMed]

12. Roseen, R.; Ballestero, T.; Houle, J.; Briggs, J.; Houle, K. Water Quality and Hydrologic Performance of a Porous Asphalt Pavement as a Storm-Water Treatment Strategy in a Cold Climate. J. Environ. Eng. 2012, 138, 81-89. [CrossRef]

13. Sansalone, J.; Teng, Z. In Situ Partial Exfiltration of Rainfall Runoff. I: Quality and Quantity Attenuation. J. Environ. Eng. 2004, 130, 990-1007. [CrossRef]

14. Guan, M.; Sillanpää, N.; Koivusalo, H. Assessment of LID Practices for Restoring Pre-Development Runoff Regime in an Urbanized Catchment in Southern Finland. Water Sci. Technol. 2015, 17, 1485-1491. [CrossRef] [PubMed]

15. Abbott, C.L.; Comino-Mateos, L. In-Situ Hydraulic Performance of a Permeable Pavement Sustainable Urban Drainage System. Water Environ. J. 2003, 17, 12-15. [CrossRef]

16. Palla, A.; Gnecco, I. Hydrologic Modeling of Low Impact Development Systems at the Urban Catchment Scale. J. Hydrol. 2015, 528, 361-368. [CrossRef]

17. Fassman, E.A.; Blackbourn, S. Urban Runoff Mitigation by a Permeable Pavement System over Impermeable Soils. J. Hydrol. Eng. 2010, 15, 475-485. [CrossRef]

18. Sañudo-Fontaneda, L.A.; Charlesworth, S.M.; Castro-Fresno, D.; Andres-Valeri, V.C.A.; Rodriguez-Hernandez, J. Water Quality and Quantity Assessment of Pervious Pavements Performance in Experimental Car Park Areas. Water Sci. Technol. 2014, 69, 1526-1533. [CrossRef] [PubMed]

19. Roseen, R.M.; Ballestero, T.P.; Houle, K.M.; Heath, D.; Houle, J.J. Assessment of Winter Maintenance of Porous Asphalt and Its Function for Chloride Source Control. J. Transp. Eng. 2014, 140, 04013007. [CrossRef]

20. Dietz, M.E. Low Impact Development Practices: A Review of Current Research and Recommendations for Future Directions. Water. Air. Soil Pollut. 2007, 186, 351-363. [CrossRef]

21. Drake, J.; Bradford, A. Assessing the Potential for Restoration of Surface Permeability for Permeable Pavements through Maintenance. Water Sci. Technol. 2013, 68, 1950-1958. [CrossRef] [PubMed]

22. Baladès, J.D.; Legret, M.; Madiec, H. Permeable Pavements: Pollution Management Tools. Water Sci. Technol. 1995, 32, 49-56. [CrossRef]

23. Kumar, K.; Kozak, J.; Hundal, L.; Cox, A.; Zhang, H.; Granato, T. In-Situ Infiltration Performance of Different Permeable Pavements in an Employee Used Parking Lot-A Four-Year Study. J. Environ. Manag. 2016, 167, 8-14. [CrossRef] [PubMed]

24. Radfar, A.; Rockaway, T.D. Clogging Prediction of Permeable Pavement. J. Irrig. Drain. Eng. 2016, 142, 04015069. [CrossRef]

25. Winston, R.J.; Al-Rubaei, A.M.; Blecken, G.T.; Viklander, M.; Hunt, W.F. Maintenance Measures for Preservation and Recovery of Permeable Pavement Surface Infiltration Rate-The Effects of Street Sweeping, Vacuum Cleaning, High Pressure Washing, and Milling. J. Environ. Manag. 2016, 169, 132-144. [CrossRef] [PubMed]

26. ASTM. Standard Test Method for Surface Infiltration Rate of Permeable Unit Pavement; ASTM: West Conshohocken, PA, USA, 2015; Volume I.

27. Helsel, D.R. Nondetects and Data Analysis. Statistics for Censored Environmental Data; John Wiley \& Sons, Inc.: Hoboken, NJ, USA, 2005.

28. Helsel, D.R. Statistics for Censored Environmental Data Using Minitab and R; John Wiley \& Sons, Inc.: Hoboken, NJ, USA, 2012.

(C) 2018 by the authors. Licensee MDPI, Basel, Switzerland. This article is an open access article distributed under the terms and conditions of the Creative Commons Attribution (CC BY) license (http:/ / creativecommons.org/licenses/by/4.0/). 